\title{
Eribulin-based neoadjuvant chemotherapy for triple-negative breast cancer patients stratified by homologous recombination deficiency status: a multicenter randomized phase II clinical trial
}

\author{
Norikazu Masuda ${ }^{1}$. Hiroko Bando ${ }^{2} \cdot$ Takashi Yamanaka $^{3} \cdot$ Takayuki Kadoya $^{4} \cdot$ Masato Takahashi $^{5}$. \\ Shigenori E. Nagai ${ }^{6}$ - Shoichiro Ohtani ${ }^{7} \cdot$ Tomoyuki Aruga $^{8} \cdot$ Eiji Suzuki $^{9}$ Yuichiro Kikawa ${ }^{10} \cdot$ Hiroyuki Yasojima $^{1}$. \\ Hiroi Kasai $^{11} \cdot$ Hiroshi Ishiguro $^{12} \cdot$ Hidetaka Kawabata $^{13} \cdot$ Satoshi Morita $^{14} \cdot$ Hironori Haga $^{15} \cdot$ Tatsuki R. Kataoka $^{15}$. \\ Ryuji Uozumi ${ }^{14} \cdot$ Shinji Ohno $^{16} \cdot$ Masakazu Toi $^{9}$
}

Received: 25 December 2020 / Accepted: 5 March 2021 / Published online: 25 March 2021

(c) The Author(s) 2021

\begin{abstract}
Purpose To investigate clinical usefulness of eribulin-based neoadjuvant chemotherapy in triple-negative breast cancer (TNBC) patients.

Methods Patients in group A (aged $<65$ years with homologous recombination deficiency, HRD, score $\geq 42$, or those at any age with germline $B R C A$ mutation, gBRCAm) were randomized to 4 cycles of paclitaxel plus carboplatin (group A1) or eribulin plus carboplatin (group A2), followed by 4 cycles of anthracycline. Patients in group B (aged $<65$ years with HRD score $<42$, or aged $\geq 65$ years without gBRCAm) were randomized to 6 cycles of eribulin plus cyclophosphamide (group B1) or eribulin plus capecitabine (group B2); non-responders to the first 4 cycles of the eribulin-based therapy received anthracycline. Primary endpoint was pCR rate (ypT0-is, ypN0; centrally confirmed). Main secondary endpoint was safety. Results The full analysis set comprised 99 patients. The pCR rate was $65 \%(90 \%$ CI, 46\%-81\%) and $45 \%(27 \%-65 \%)$ in groups A1 and A2, respectively, and 19\% (8\%-35\%) in both groups B1 and B2. No major difference was seen in secondary endpoints, but peripheral neuropathy incidence was $74 \%$ in group A1, whereas it was 32\%, 22\%, and 26\% in groups A2, B1, and $\mathrm{B} 2$, respectively.

Conclusions In patients aged $<65$ years with high HRD score or gBRCAm, weekly paclitaxel plus carboplatin and eribulin plus carboplatin followed by anthracycline resulted in a pCR rate of $>60 \%$ and $>40 \%$, respectively, suggesting potential usefulness of patient stratification using HRD; pCR tended to be low in patients with HRD-negative tumors. Neurotoxicity was less frequent with the eribulin-based regimen. Trial registration:The study has been registered with the University Hospital Medical Information Network Clinical Trials Registry (http://www.umin.ac.jp/ctr/index-j.htm) with unique trial number UMIN000023162. The Japan Breast Cancer Research Group trial number is JBCRG-22.
\end{abstract}

Keywords BRCA mutation status · Eribulin · Homologous recombination deficiency score $\cdot$ Neoadjuvant chemotherapy Pathological complete response $\cdot$ Triple-negative breast cancer

\section{Introduction}

Triple-negative breast cancer (TNBC), which accounts for about $10-20 \%$ of breast cancers, is an aggressive subtype with a poor prognosis $[1,2]$. Because it lacks specific targets for treatment $[1,2]$, research is being directed toward

Norikazu Masuda

nmasuda@alpha.ocn.ne.jp

Extended author information available on the last page of the article improving neoadjuvant chemotherapy for TNBC. Pathological complete response (pCR) correlates with favorable prognosis [3-6] and is used to gauge the success of new regimens. Patients with TNBC typically receive anthracycline- and taxane-based perioperative regimens. However, these have limited success [7], so new regimens including addition of chemotherapeutic agents to existing regimens have been proposed as a way to improve pCR rate $[8,9]$.

Previously, our research group investigated neoadjuvant chemotherapy regimens with an anthracycline-docetaxel combination [10-13]. For TNBC, we conducted a phase II 
study of neoadjuvant metronomic chemotherapy with paclitaxel, cyclophosphamide, and capecitabine followed by an anthracycline-containing regimen (JBCRG-13), which resulted in a high pCR rate (intent-to-treat population, 47.5\%) with acceptable tolerability [14].

As our next research target, we consider treatment with eribulin, a novel microtubule inhibitor, to be potentially useful as an alternative to taxane-based regimens for TNBC. Eribulin disrupts mitosis by inhibiting the microtubule growth phase without affecting the shortening phase [15-18]. Distinct effects of eribulin include vascular remodeling $[19,20]$ and suppression of epithelial-mesenchymal transition [21, 22]. These unique mechanisms of action make it efficacious in cases of residual cancer or resistance to standard neoadjuvant chemotherapy including taxanes $[19,23,24]$, and it particularly benefits TNBC patients [25]. Moreover, the incidence of peripheral neuropathy, a frequent adverse effect of taxanes, tends to be low with eribulin [22, $24,25]$.

One of the aims of the present study was to use response predictors to identify patients most likely to benefit from chemotherapy. Therefore, we stratified TNBC patients by homologous recombination deficiency (HRD) score [26] and germline BRCA mutation (gBRCAm) status [27], both of which are effective predictors for $\mathrm{pCR}$, particularly when patients are treated with platinum-containing chemotherapy. HRD scores correlate strongly with BRCAl/2 deficiency, regardless of breast cancer subtype [28]. We evaluated their usefulness as response predictors in TNBC patients receiving carboplatin in combination with standard paclitaxel- or eribulin-based regimens, for the following reasons. Addition of carboplatin to standard neoadjuvant anthracycline- and taxane-based chemotherapy has been shown to improve pCR rate in patients with HER2-negative breast cancer [29] or TNBC [8, 30, 31]. Alternatively, eribulin plus carboplatin could be used as neoadjuvant chemotherapy for TNBC, to avoid peripheral neuropathy caused by taxanes. In a study in which patients with early-stage TNBC received four cycles of carboplatin plus eribulin, pCR was confirmed in 13 (43.3\%) of 30 patients; 12 of 26 patients had HRD-positive tumors, and of them, 9 patients achieved pCR, suggesting that HRD-positive status may predict pCR in TNBC patients receiving this treatment [32].

Additionally, for elderly patients or those without gBRCAm, we aimed to investigate a potentially less toxic regimen of eribulin combined with capecitabine or cyclophosphamide. To avoid cardiotoxicity caused by anthracyclines $[33,34]$, non-anthracycline regimens are being investigated. One example is docetaxel plus cyclophosphamide (TC) [35-37]; however, TC is insufficiently efficacious against certain cancer subtypes (e.g., basal-like/BRCAness phenotype) [36]. Therefore, in elderly patients and those without gBRCAm, we investigated treatment de-escalation by using eribulin in combination with cyclophosphamide or capecitabine. The safety of eribulin plus capecitabine had previously been confirmed in a phase I study (JBCRG-18) [38].

Our primary aim of the present study was to investigate the clinical usefulness of eribulin-containing neoadjuvant regimens for TNBC by means of stratification by HRD score and gBRCAm status. We also aimed to explore the option of potentially less toxic regimens for elderly TNBC patients.

\section{Methods}

\section{Study design}

In this multicenter randomized parallel-group phase II clinical trial, the main inclusion criteria were: diagnosis of primary TNBC (resectable tumor; cT1c-cT3, cN0-cN1, and cM0) confirmed as invasive by centralized pathologic review (CPR); diameter $\leq 70 \mathrm{~mm}$; Ki67 labeling index $\geq 10 \%$ (if available). Patients who met the criteria for primary registration were subjected to CPR (based at Kyoto University Hospital, Kyoto, Japan), and those who met the additional criteria for secondary registration were enrolled (Fig. 1). Details of inclusion/exclusion criteria are provided as Supplementary information.

\section{Randomization and allocation to treatment groups}

Random allocation was performed by the registration center, using the minimization method. The adjustment factors were age at secondary registration ( $<50$ years or $\geq 50$ years), tumor diameter ( $\mathrm{T} ;<30 \mathrm{~mm}$ or $\geq 30 \mathrm{~mm})$, axillary lymph node (ALN) status ( $\mathrm{N}$; $\mathrm{cN} 0$, or $\mathrm{cN}(+))$, and Ki67 labeling index $(<30 \%$ or $\geq 30 \%)$.

Patients were allocated to two groups based on HRD score, gBRCAm status (if available), and age at time of informed consent. Group A included patients aged $<65$ years and with HRD score $\geq 42$, and all patients with gBRCAm. Group B included patients aged $<65$ years and with HRD score $<42$, and all patients aged $\geq 65$ years except those with gBRCAm. The rationale for patient allocation to groups A and $\mathrm{B}$ was based on the expectation of a good response to platinum-containing chemotherapy in patients with high HRD score or gBRCAm (group A) [27, 32, 39, 40] and the investigation of potentially less toxic regimens for older patients (group B).

\section{Treatment}

Figure 2 shows the dosing schedule. In group A, patients were randomized to either group A1, receiving a standard taxane and platinum regimen (paclitaxel plus carboplatin) followed by an anthracycline-based regimen 


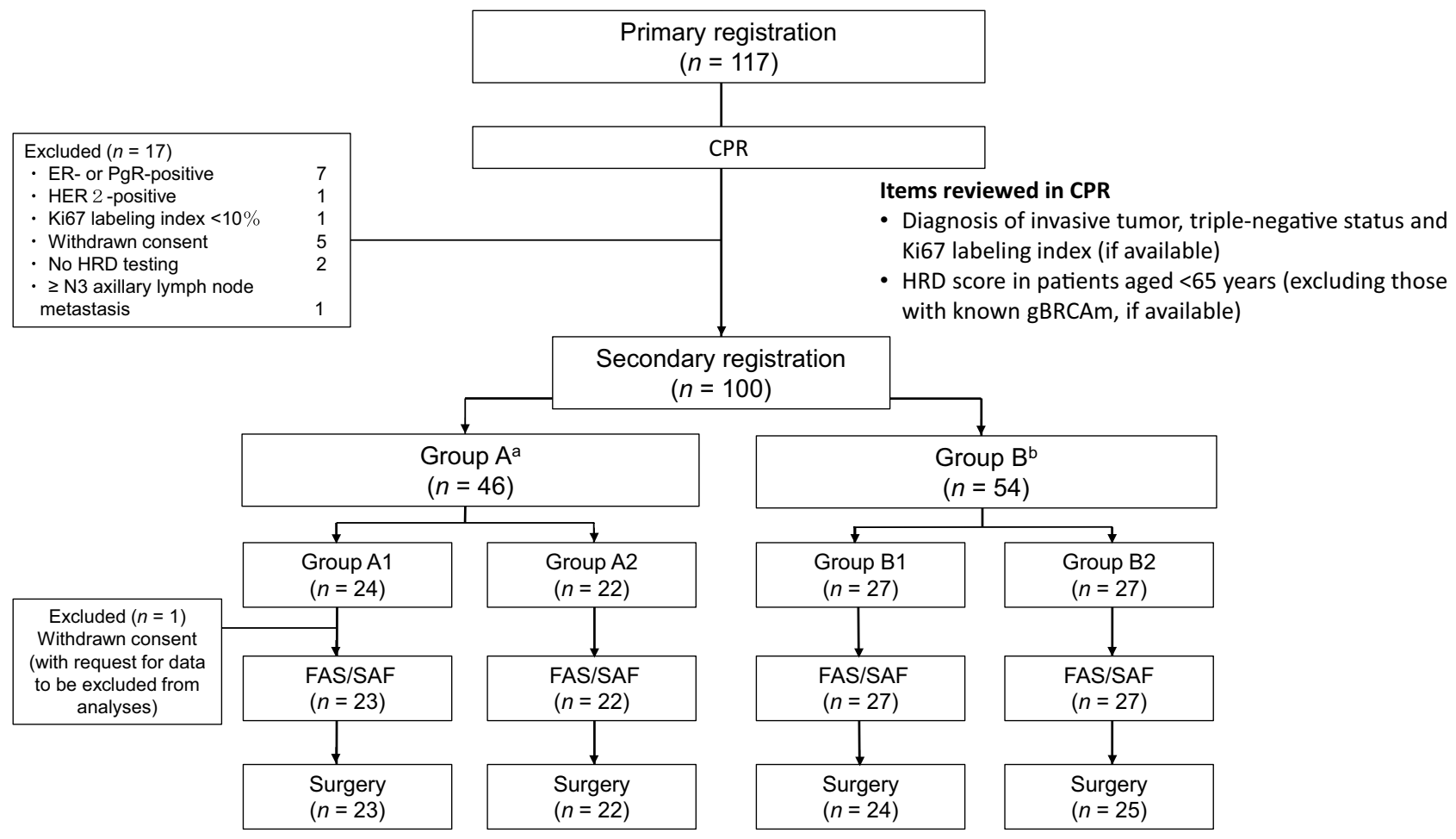

Fig. 1 Study flow and patient disposition. a Group A included patients aged $<65$ years and with HRD score $\geq 42$, and all patients with gBRCAm. ${ }^{\text {b}}$ Group B included patients aged $<65$ years and with HRD score $<42$, and all patients aged $\geq 65$ years except those with gBRCAm. gBRCAm, germline BRCA mutation; CPR, centralized path-

(5-fluorouracil-epirubicin-cyclophosphamide, FEC or doxorubicin-cyclophosphamide, AC), or group A2, receiving the same regimen except with eribulin instead of paclitaxel. The antitumor effects of the initial therapy were evaluated at cycle 4 by MRI (mandatory) or PET-CT. Core needle biopsy (CNB) was also performed at cycle 4 , when possible, to determine pathological response.

In group B, patients were randomized to either group B1, receiving a regimen combining eribulin with cyclophosphamide, or group B2, receiving a regimen combining eribulin with capecitabine. At cycle 4, the antitumor effects of the initial therapy were evaluated by MRI or PET-CT to determine complete response (CR), partial response (PR) stable disease (SD), or progressive disease (PD) and determine tumor diameter $(<10 \mathrm{~mm}$ or $\geq 10 \mathrm{~mm})$. In cases of SD or PD, CNB was performed to determine whether patients had residual invasive tumor. Patients with CR or PR, and those with SD but no residual invasive tumor, received two further cycles of the eribulin-based regimen before surgery. Patients with SD and confirmation of residual invasive tumor were switched to 4 cycles of FEC or AC (rescue regimen) before surgery. Patients with PD were switched to the rescue regimen followed by surgery, or surgery. For the patients who received the additional cycles of eribulin plus cyclophosphamide or

ologic review; ER, estrogen receptor; FAS, full analysis set; HER2, human epidermal growth factor receptor 2; HRD, homologous recombination deficiency; PgR, progesterone receptor; SAF, safety analysis set

capecitabine, the antitumor effects were evaluated at cycle 6 . Patients with tumor diameter $<10 \mathrm{~mm}$, or with tumor diameter $\geq 10 \mathrm{~mm}$ and no residual invasive tumor, underwent surgery. Patients with tumor diameter $\geq 10 \mathrm{~mm}$ and confirmation of residual invasive tumor received the rescue regimen followed by surgery, or surgery.

The treatment was initiated within 2 weeks of secondary registration. Each cycle lasted 21 days.

\section{Surgery}

Mastectomy or breast-conserving surgery (BCS) was carried out as a curative surgery within 11 weeks of the start of the final cycle of chemotherapy. The decision of which surgical procedure to choose was based on the spread of residual tumor by imaging and the preference of the individual patient, with the aim of obtaining adequate negative margins.

\section{Assessment of efficacy and safety}

Pathologic response was assessed by examination (at each participating institution and by the CPR committee) of hematoxylin-eosin-stained tissue samples removed during 


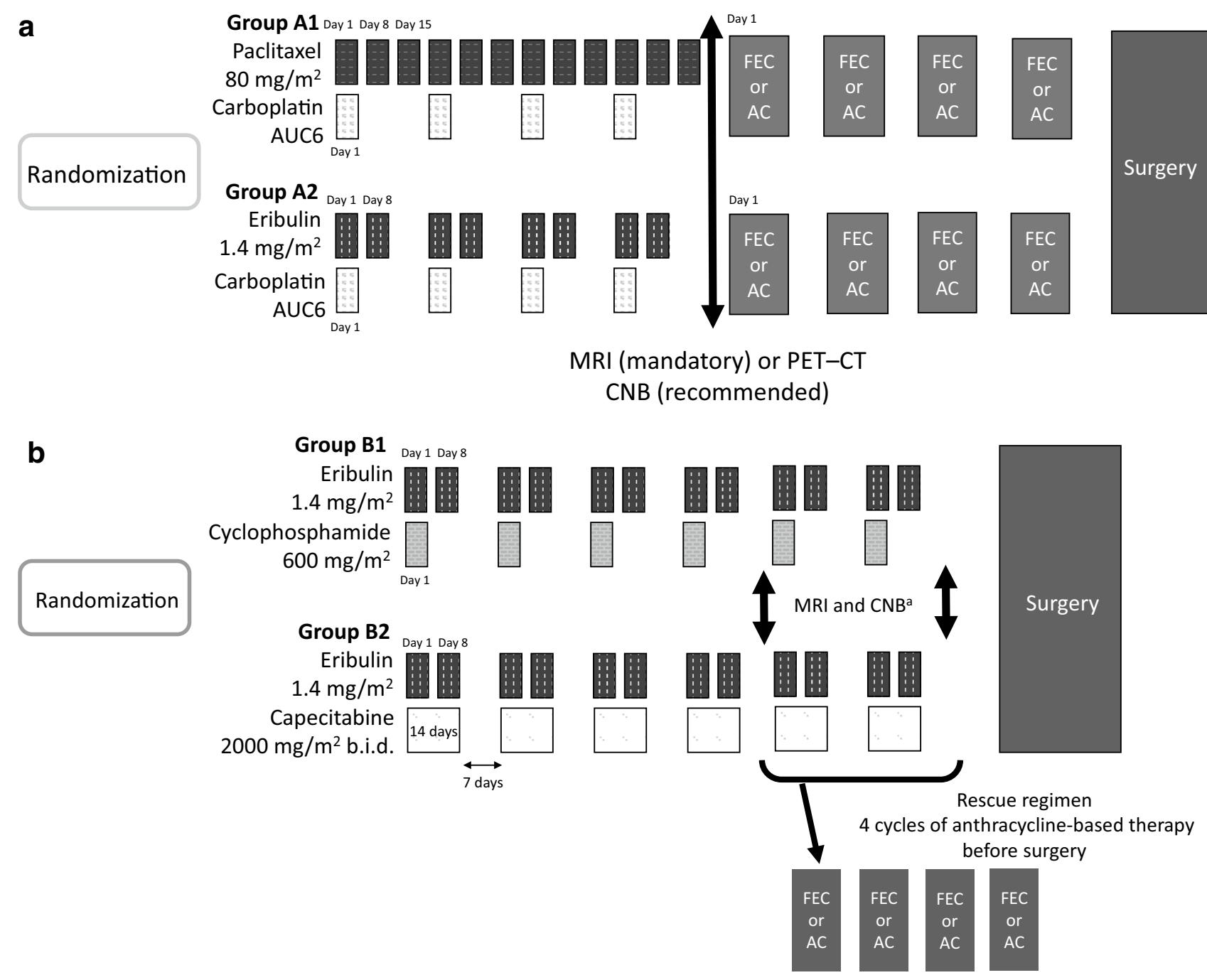

\begin{abstract}
${ }^{a}$ At cycle 4, MRI was used to identify patients with SD or PD, who then underwent CNB; those found to have residual invasive cancer then received the rescue regimen. At cycle 6 , it was performed in patients with tumor $\geq 1 \mathrm{~cm}$; those found to have residual invasive cancer then received the rescue regimen.
\end{abstract}

Fig. 2 Dosing schedule. a Patients in group A1 received 4 cycles of combination therapy with paclitaxel $\left(80 \mathrm{mg} / \mathrm{m}^{2}\right)$ on days 1,8 , and 15 of each cycle and carboplatin (AUC6) on day 1. Patients in group A2 received 4 cycles of combination therapy with eribulin $(1.4 \mathrm{mg} /$ $\mathrm{m}^{2}$ ) on days 1 and 8 of each cycle and carboplatin (AUC6) on day 1 . Depending on the antitumor effects of the initial therapy, evaluated at cycle 4 , patients subsequently received the anthracycline-based regimen before surgery, or discontinued chemotherapy and underwent surgery. The anthracycline-based regimen comprised FEC, consisting of 5 -fluorouracil $\left(500 \mathrm{mg} / \mathrm{m}^{2}\right)$, epirubicin $\left(100 \mathrm{mg} / \mathrm{m}^{2}\right)$, and cyclophosphamide $\left(500 \mathrm{mg} / \mathrm{m}^{2}\right)$; or AC, consisting of doxorubicin $(60 \mathrm{mg} /$ $\left.\mathrm{m}^{2}\right)$ and cyclophosphamide $\left(600 \mathrm{mg} / \mathrm{m}^{2}\right)$, on day 1 of each cycle. b Patients in group B1 received 4 cycles of eribulin $\left(1.4 \mathrm{mg} / \mathrm{m}^{2}\right)$ on

surgery (operative specimens). Based on examination of the primary lesion, pathologic response was classified as strict pCR (SpCR; no residual tumor), comprehensive pCR (CpCR; SpCR or residual ductal carcinoma in situ), or quasi days 1 and 8 of each cycle and cyclophosphamide $\left(600 \mathrm{mg} / \mathrm{m}^{2}\right)$ on day 1. Patients in group B2 received 4 cycles of eribulin $(1.4 \mathrm{mg} /$ $\left.\mathrm{m}^{2}\right)$ on days 1 and 8 of each cycle and capecitabine $\left(2000 \mathrm{mg} / \mathrm{m}^{2} /\right.$ day) administered orally twice daily on days $1-14$. Depending on the antitumor effects, assessed at cycle 4, patients in groups B1 and B2 received an additional 2 cycles of the eribulin-based regimen before surgery, or underwent surgery after receiving the rescue regimen (FEC or AC as described for group A). AC, doxorubicin-cyclophosphamide regimen; $\mathrm{CNB}$, core needle biopsy; $\mathrm{CT}$, computed tomography; FEC, 5-fluorouracil-epirubicin-cyclophosphamide regimen; MRI, magnetic resonance imaging; PD, progressive disease; PET, positron emission tomography; $\mathrm{SD}$, stable disease

pCR (QpCR; CpCR plus near pCR [small foci of cancer cells]). Specimens from ALNs were also examined, and metastasis in the ALNs (including isolated tumor cell clusters) of $\leq 0.2 \mathrm{~mm}$ was defined as ypN0. Clinical response 
was assessed based on the Response Evaluation Criteria in Solid Tumors version 1.1.

Adverse events (AEs), defined as any unfavorable or unintended sign that may or may not be associated with the study treatment, were recorded and graded according to the National Cancer Institute Common Terminology Criteria for Adverse Events, version 4.0 (Japanese Clinical Oncology Group edition) [41].

\section{Endpoints}

The primary endpoint was $\mathrm{CpCR}$ (ypT0ypN0 or ypTisypN0) rate. Secondary endpoints for efficacy included proportion of patients with SpCR or SpCR plus ypN0, CpCR, and QpCR or QpCR plus ypN0; clinical response rate (i.e., response rate to the eribulin-based regimen and the anthracyclinebased regimen, and overall response rate); BCS rate (BCSR); and proportion of patients whose ALN status had become negative by the time of surgery. Tumor regression from baseline (or the start of FEC or AC) to completion of neoadjuvant chemotherapy was assessed. Secondary endpoints for safety were incidence of AEs, treatment completion rate, and relative dose intensity.

\section{Statistical analyses}

When setting an $\alpha$ error of 0.05 (one-sided) and a power of $80 \%$ with a threshold pCR rate of 0.40 and an expected pCR rate of 0.60 for group A, and a threshold pCR rate of 0.35 and an expected $\mathrm{pCR}$ rate of 0.55 for group $\mathrm{B}$, the maximum required numbers of patients were calculated as 88 for group A (44 for each of groups A1/A2) and 90 for group B (45 for each of groups B1/B2). Allowing for patients excluded from analyses, the target number was determined as 100 for each of groups A and B.

Efficacy was evaluated using data from all patients in the full analysis set (FAS), defined as all patients who fulfilled the inclusion criteria and received $\geq 1$ dose of a study drug. Safety was evaluated using data from the safety analysis set (SAF), comprising all patients who received $\geq 1$ dose of a study drug.

For the primary endpoint (i.e., pCR rate), and the secondary endpoints of SpCR rate and SpCR plus ypN0 rate, overall response rate, and BCSR, point estimates and two-sided 90\% or 95\% Clopper-Pearson exact CIs were calculated for groups A1, A2, B1, and B2. Because our primary aim in this phase II trial was to assess the therapeutic efficacy of candidate chemotherapeutic regimens for TNBC, our focus was the efficacy endpoints for each group rather than intergroup comparisons. However, for exploratory purposes, we also calculated $P$ values using Fisher's exact test for comparisons within groups A and B (i.e., group A1 versus A2, and group B1 versus B2).

Statistical analyses were performed using SAS software, version 9.4 (SAS Institute, Cary, NC, USA).

\section{Results}

\section{Participant flow}

Patients were recruited in Japan between February 2017 and January 2019. Recruitment ended when 100 patients had been found to have met the criteria for secondary registration.

Of the 117 patients initially recruited, 100 met the criteria for secondary registration. One patient in group A1 withdrew consent after secondary registration. In accordance with the patient's request, their data were excluded from all analyses. Consequently, both the FAS and SAF comprised 99 patients (Fig. 1).

\section{Baseline data}

Most baseline characteristics were well balanced between the groups (Table 1). Age at secondary registration was higher in group B than in group A, due to age being a factor in the patient allocation to treatment groups. Group A included no patients aged $\geq 65$ years. Histological grade tended to be higher in group A than in group B. All patients had invasive ductal carcinoma.

\section{Completion of planned treatment}

\section{Group A}

Mean relative dose intensity was $87.1 \%$ for paclitaxel (group A1) and $83.9 \%$ for eribulin (group A2). For carboplatin, it was $96.4 \%$ and $96.6 \%$ in groups $\mathrm{A} 1$ and $\mathrm{A} 2$, respectively. After initially receiving $\leq 4$ cycles of the paclitaxel- or eribulin-based regimen, 96\% (22/23) and 95\% (21/22) of patients in groups $\mathrm{A} 1$ and $\mathrm{A} 2$, respectively, received $\geq 1$ cycle of one of the subsequent anthracycline-based regimens.

\section{Group B}

In groups B1 and B2, 48\% (13/27) and 56\% (15/27) of patients, respectively, completed all 6 cycles of the planned eribulin-based therapy. Details of the completion of planned treatment are summarized in Supplementary Fig. S1. 
Table 1 Baseline patient characteristics ${ }^{\mathrm{a}}$

\begin{tabular}{|c|c|c|c|c|}
\hline Characteristic & Group A1 $(n=23)$ & Group A2 $(n=22)$ & Group B1 $(n=27)$ & Group B2 $(n=27)$ \\
\hline \multicolumn{5}{|c|}{ Age at secondary registration, years } \\
\hline Mean \pm SD & $47.4 \pm 11.0$ & $47.3 \pm 11.3$ & $59.3 \pm 8.4$ & $58.8 \pm 9.1$ \\
\hline Median (minimum, maximum) & $44.0(28,64)$ & $47.5(26,63)$ & $59.0(35,70)$ & $60.0(37,70)$ \\
\hline \multicolumn{5}{|c|}{ Age category at secondary registration, years } \\
\hline$<50$ & $14(61)$ & $13(59)$ & $3(11)$ & $3(11)$ \\
\hline$\geq 50$ & $9(39)$ & $9(41)$ & $24(89)$ & $24(89)$ \\
\hline \multicolumn{5}{|c|}{ TNM classification: $T$ (primary lesion) } \\
\hline T1c & $10(43)$ & $6(27)$ & $2(7)$ & $7(26)$ \\
\hline $\mathrm{T} 2$ & $12(52)$ & $14(64)$ & $23(85)$ & $17(63)$ \\
\hline $\mathrm{T} 3$ & $1(4)$ & $2(9)$ & $2(7)$ & $3(11)$ \\
\hline \multicolumn{5}{|c|}{ Tumor size (primary lesion), $\mathrm{mm}$} \\
\hline Mean \pm SD & $27.4 \pm 12.2$ & $31.0 \pm 13.9$ & $33.7 \pm 13.8$ & $32.1 \pm 17.1$ \\
\hline Median (minimum, maximum) & $23.0(13,60)$ & $26.5(13,64)$ & $30.0(12,70)$ & $26.0(12,92)$ \\
\hline \multicolumn{5}{|c|}{ TNM classification: $\mathbf{N}$ (regional lymph node) } \\
\hline No & $15(65)$ & $14(64)$ & $16(59)$ & $17(63)$ \\
\hline N1 & $8(35)$ & $8(36)$ & $11(41)$ & $10(37)$ \\
\hline \multicolumn{5}{|l|}{ Type of invasive carcinoma } \\
\hline Ductal & $23(100)$ & $22(100)$ & $27(100)$ & $27(100)$ \\
\hline Lobular & 0 & 0 & 0 & 0 \\
\hline \multicolumn{5}{|l|}{ Histological grade (B\&R) } \\
\hline 1 & $1(4)$ & 0 & 0 & $3(11)$ \\
\hline 2 & $3(13)$ & $4(18)$ & $8(30)$ & $8(30)$ \\
\hline 3 & $16(70)$ & $17(77)$ & $18(67)$ & $12(44)$ \\
\hline \multicolumn{5}{|l|}{ HER2 status ${ }^{b}$} \\
\hline 0 & $21(91)$ & $14(64)$ & $19(70)$ & $18(67)$ \\
\hline $1+$ & $2(9)$ & $7(32)$ & $5(19)$ & $6(22)$ \\
\hline $2+$ & 0 & 0 & $3(11)$ & $3(11)$ \\
\hline \multicolumn{5}{|l|}{ Ki67 index, $\%^{c}$} \\
\hline$n$ & 23 & 22 & 27 & 27 \\
\hline Mean \pm SD & $55.1 \pm 21.4$ & $66.7 \pm 16.9$ & $55.3 \pm 23.0$ & $50.0 \pm 19.9$ \\
\hline Median (minimum, maximum) & $58.0(20.2,92.4)$ & $66.2(36.4,89.6)$ & $51.6(16.4,90.4)$ & $48.0(16.2,82.0)$ \\
\hline \multicolumn{5}{|l|}{ Ki67 index, category ${ }^{b}$} \\
\hline$<30 \%$ & $3(13)$ & 0 & $5(19)$ & $6(22)$ \\
\hline$\geq 30 \%$ & $20(87)$ & $22(100)$ & $22(81)$ & $21(78)$ \\
\hline
\end{tabular}

B\&R, Bloom and Richardson grading system; HER2, human epidermal growth factor receptor 2

${ }^{\text {a }}$ Values are $n(\%)$ unless otherwise stated

${ }^{\mathrm{b}}$ Confirmed immunohistochemically by centralized pathologic review

${ }^{\mathrm{c}}$ Confirmed by centralized pathologic review

\section{Primary endpoint}

Table 2 shows the proportion of patients achieving pCR. In group A1, 15 of 23 patients $(65 \%$; $90 \% \mathrm{CI}, 46 \%-81 \%)$ achieved pCR. In group A2, 10 of 22 patients (45\%; $90 \%$ CI, 27\%-65\%) achieved pCR; the pCR rate for group A1 met its primary objective (lower bound of $90 \% \mathrm{CI},>40 \%$ ). The pCR rate for groups B1 and B2 (19\%, 90\% CI, $8 \%-35 \%$ for each group) was below the threshold pCR rate (35\%) predefined for group B.

\section{Secondary efficacy endpoints}

\section{Pathological response and clinical response}

Table 3 shows the proportion of patients achieving SpCR plus pNO, CpCR, and QpCR plus pNO. Table 4 shows the results for clinical response at cycle 4 and completion of neoadjuvant chemotherapy. 
Table 2 Pathological complete response (pCR; ypT0ypNO or ypTisypN0) rate (primary endpoint): the proportion of patients achieving pCR

\begin{tabular}{llrl}
\hline Group & $\begin{array}{l}\text { No. of patients } \\
\text { achieving pCR }\end{array}$ & pCR rate, \% $\left(90 \% \mathrm{CI}^{\mathrm{a}}\right)$ & $P^{\mathrm{b}}$ \\
\hline A1 $(n=23)$ & 15 & $65(46-81)$ & 0.24 \\
A2 $(n=22)$ & 10 & $45(27-65)$ & \\
B1 $(n=27)$ & 5 & $19(8-35)$ & 1.00 \\
B2 $(n=27)$ & 5 & $19(8-35)$ & \\
\hline
\end{tabular}

${ }^{\mathrm{a}}$ Clopper-Pearson exact confidence interval

${ }^{b}$ Fisher's exact test: group A1 versus group A2 or group B1 versus group B2

\section{Tumor response}

Figure 3 shows tumor size reduction in individual patients. In groups A1 and A2, 9 and 6 patients, respectively, had $100 \%$ tumor size reduction after initial paclitaxel- or eribulin-based regimen, and 13 and 10 patients, respectively, achieved CR after completion of anthracycline regimen (Fig. 3a). In groups B1 and B2, 2 patients and 4 patients, respectively, had $100 \%$ tumor size reduction after eribulin plus cyclophosphamide or capecitabine regimen (Fig. 3b).

Tumor size reduction from the start of anthracycline to completion of neoadjuvant chemotherapy is shown in Supplementary Fig. S2.

Table 3 Strict pathological complete response (SpCR) plus pN0, comprehensive pathological complete response (CpCR), and quasi pathological complete response (QpCR) plus pN0 rates (secondary endpoints for efficacy)

\begin{tabular}{|c|c|c|c|c|c|c|}
\hline Variable & Group A1 $(n=23)$ & Group A2 $(n=22)$ & $P^{\mathrm{b}}$ & Group B1 $(n=27)$ & Group B2 $(n=27)$ & $P^{\mathrm{b}}$ \\
\hline No. of patients achieving SpCR plus pN0 & 14 & 8 & & 2 & 5 & \\
\hline SpCR plus pN0 rate, $\%\left(90 \% \mathrm{CI}^{\mathrm{a}}\right)$ & $61(42-78)$ & $36(20-56)$ & 0.14 & $7(1-22)$ & $19(8-35)$ & 0.42 \\
\hline No. of patients achieving CpCR & 16 & 12 & & 6 & 7 & \\
\hline CpCR rate, $\%\left(90 \% \mathrm{CI}^{\mathrm{a}}\right)$ & $70(50-85)$ & $55(35-73)$ & 0.37 & $22(10-39)$ & $26(13-43)$ & 1.00 \\
\hline No. of patients achieving QpCR plus pN0 & 16 & 11 & & 8 & 6 & \\
\hline QpCR plus pN0 rate, $\%\left(90 \% \mathrm{CI}^{\mathrm{a}}\right)$ & $70(50-85)$ & $50(31-69)$ & 0.23 & $30(16-47)$ & $22(10-39)$ & 0.76 \\
\hline
\end{tabular}

${ }^{\mathrm{a} C l o p p e r-P e a r s o n ~ e x a c t ~ c o n f i d e n c e ~ i n t e r v a l ~}$

${ }^{\mathrm{b}}$ Fisher's exact test

Table 4 Clinical response and overall response rate (confirmed by MRI or contrast CT examination)

\begin{tabular}{llllllll}
\hline Group & \multicolumn{3}{l}{ No. of patients achieving clinical response } & & $\begin{array}{l}\text { Overall response rate, } \\
\%\left(95 \% \mathrm{CI}^{\mathrm{a}}\right)\end{array}$ & $P^{\mathrm{b}}$ \\
\cline { 2 - 5 } & $\mathrm{CR}$ & $\mathrm{PR}$ & $\mathrm{SD}$ & $\mathrm{PD}$ & $\mathrm{NE}^{\mathrm{d}}$ & & \\
\hline At cycle 4 & & & & & & & \\
A1 $(n=23)$ & 8 & 13 & 1 & 0 & 1 & $91(72-99)$ & 0.41 \\
A2 $(n=22)$ & 6 & 12 & 2 & 1 & 1 & $82(60-95)$ & 1.00 \\
B1 $(n=27)$ & 2 & 12 & 8 & 4 & 1 & $52(32-71)$ & \\
B2 $(n=27)$ & 3 & 11 & 11 & 2 & 0 & $52(32-71)$ & \\
At completion of neoadjuvant chemotherapy & & & & \\
A1 $(n=23)$ & 11 & 9 & 1 & 0 & 2 & $87(66-97)$ & 0.46 \\
A2 $(n=22)$ & 9 & 8 & 1 & 2 & 2 & $77(55-92)$ & \\
B1 $(n=27)^{\mathrm{e}}$ & 4 & 11 & 4 & 6 & 2 & $56(35-75)$ & \\
B2 $(n=27)^{\mathrm{e}}$ & 5 & 13 & 5 & 3 & 1 & $67(46-84)$ & \\
\hline
\end{tabular}

$\mathrm{CR}$, complete response; NE, not evaluable; PD, progressive disease; PR, partial response; SD, stable disease

${ }^{\mathrm{a}}$ Clopper-Pearson exact confidence interval

${ }^{\text {b}}$ Fisher's exact test: group A1 versus A2 or group B1 versus group B2

${ }^{\mathrm{c}}$ Patients who dropped out prior to cycle 4 or completion of neoadjuvant chemotherapy were considered not to have had a response (non-responder imputation)

${ }^{\mathrm{d}}$ Data were not evaluable because treatment was switched to surgery; the target lesion lymph node was located outside the imaging area or not detected before the start of treatment; or the imaging test was not performed at the evaluation times

${ }^{\mathrm{e}}$ In groups B1 and B2, 13 and 15 patients, respectively, completed the planned 6 cycles of treatment; 9 patients in each of groups B1 and B2 were switched to receive anthracycline-based regimens based on imaging test results at cycle 4 
a

Group A1

$(n=23)$

Group A2

$(n=22)$



After paclitaxel (group A1) or eribulin (group A2) plus carboplatin regimen

At completion of neoadjuvant chemotherapy after addition of anthracycline regimen (response)

At completion of neoadjuvant chemotherapy after addition of anthracycline regimen (progression)

b

Group B1

$(n=26)$
Group B2

$(n=26)$

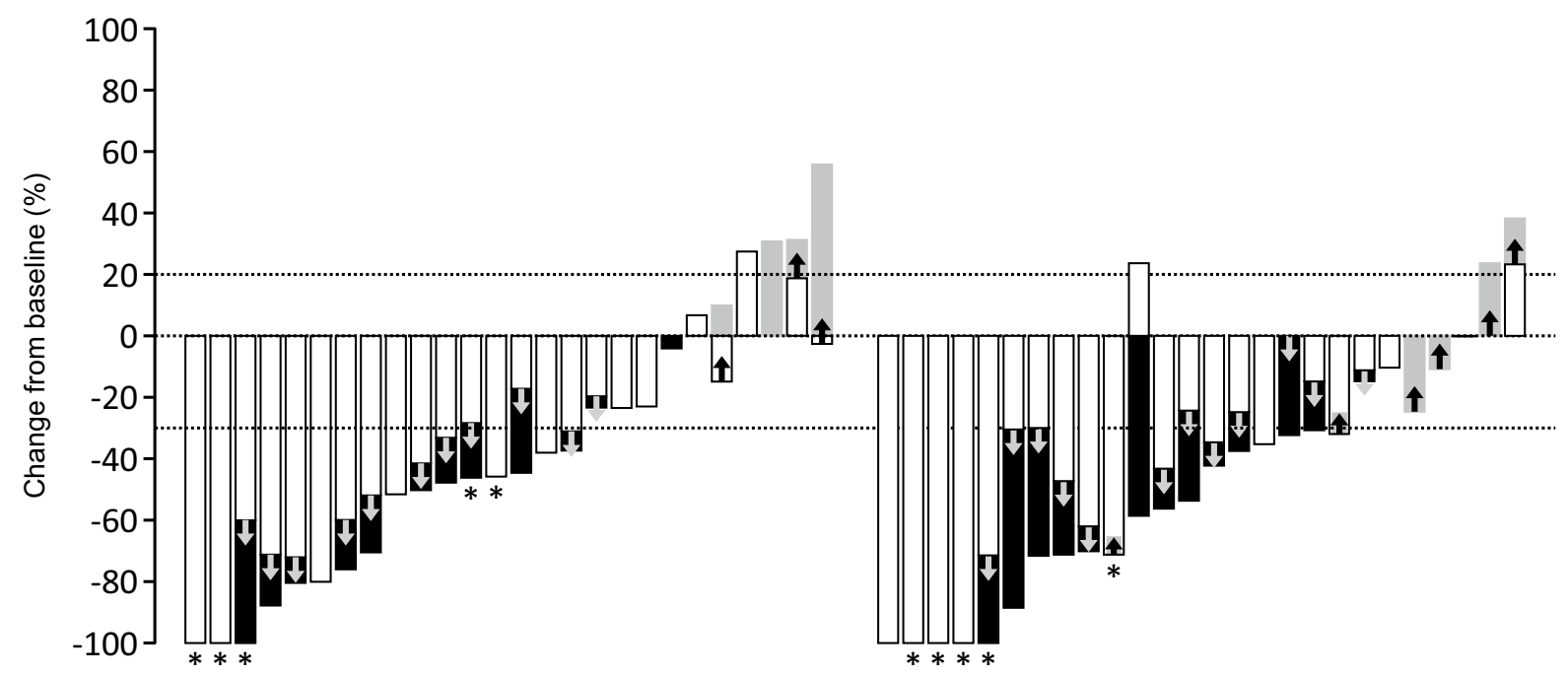

After eribulin plus cyclophosphamide (group B1) or capecitabine (group B2) regimen

At completion of neoadjuvant chemotherapy after addition of anthracycline regimen (response) At completion of neoadjuvant chemotherapy after addition of anthracycline regimen (progression)

Fig. 3 Waterfall plots showing change in tumor size from baseline a in group A1 $(n=23)$ and group A2 $(n=22)$ after the initial paclitaxel or eribulin plus carboplatin regimen and at completion of neoadjuvant chemotherapy, and $\mathbf{b}$ in group B1 $(n=26)$ and group B2 $(n=26)$ after the eribulin plus cyclophosphamide (group B1) or capecit- abine (group B2) regimen and at completion of neoadjuvant chemotherapy. In group B, data of 2 patients (1 each in groups B1 and B2) who dropped out before cycle 4 are not shown. Asterisks (*) indicate patients with pathological complete response (CpCRypNO) 
In group A, tumor regression in response to subsequent anthracycline in the patients who had initially received paclitaxel (group A1, $n=12$ ) and those who had received eribulin (group A2, $n=14$ ) was -56.0 (95\% CI, -77.6 to -34.5 ) and $-53.5(-76.7$ to -30.3$)$, respectively. The mean change in tumor size at completion of neoadjuvant chemotherapy tended to be similar between groups A1 and A2 (Supplementary Fig. S3).

\section{Breast-conserving surgery rate}

In groups $\mathrm{A} 1$ and $\mathrm{A} 2,8$ of the 23 patients and 13 of the 22 patients, respectively, underwent BCS. Point estimates were $26 \%$ (95\% CI, 10\%-48\%) for group A1 and 55\% (95\% CI, $32 \%-76 \%$ ) for group A2. In group B1 and B2, 9 of the 24 patients and 13 of the 25 patients, respectively, underwent BCS. Point estimates were 29\% (95\% CI, 13\%-51\%) for group B1 and 40\% (95\% CI, 21\%-61\%) for group B2.

\section{Axillary lymph node status}

The numbers of previously lymph node-positive patients who were lymph node-negative at surgery were 7 of 8 in group A1 and 6 of 8 in group A2, and 5 of 11 in group B1 and 2 of 10 in group B2 (Table 5).

\section{Adverse events}

The results for AEs are summarized in Table 6. In group A, the incidence of peripheral sensory neuropathy was lower in patients who received the eribulin-based regimen than in those who received the paclitaxel-based regimen $(32 \%$ and $74 \%$, respectively). All cases of serious AEs improved or resolved with appropriate treatment. No deaths were recorded. Overall, the incidence of AEs was similar to in previous studies.

\section{Discussion}

In the present study, the number of enrolled patients did not reach the target sample size. This may be partly because other studies enrolling TNBC patients were ongoing at about the same time. Also, the study procedures, including HRD testing, were time-consuming (e.g. it took about 3 weeks to obtain the test results and determine HRD status by CPR), which made it difficult to obtain consent from patients who wished to start treatment immediately. However, the requisite number of patients for the analyses of safety and efficacy of the new regimens was eventually enrolled and data from a randomized phase II trial were obtained. To our knowledge, this is the first study that evaluated neoadjuvant eribulin for
TNBC based on stratification by HRD score and gBRCAm status in the prospective randomized setting.

\section{Clinical usefulness of the eribulin-carboplatin neoadjuvant regimen}

In group A, we investigated the standard paclitaxel or eribulin plus carboplatin regimens, each followed by FEC or AC. Recently, a study of neoadjuvant eribulin followed by FEC has been reported; pCR was achieved by a relatively low proportion of patients $(8 / 43,19 \%)$ [42]. Our study is new in that carboplatin was added to the initial paclitaxel- or eribulin-based therapy based on stratification of patients by HRD score and gBRCAm status; in both cases this resulted in high pCR rate ( $65 \%$ and $45 \%$, respectively). Mean relative dose intensity for paclitaxel, eribulin, and carboplatin exceeded the recommended minimum of $80 \%$.

A recent meta-analysis (nine randomized controlled trials, $\mathrm{N}=2109$ ) has shown pCR to be significantly higher in TNBC patients treated with platinum-based as opposed to platinum-free neoadjuvant chemotherapy $(52.1 \%$ versus $37.0 \%$ ) [43]. In the phase II study of neoadjuvant carboplatin plus eribulin for TNBC, HRD score and HRD status were found to be predictors of pCR in an exploratory analysis [32]. Our results support these findings, confirming the usefulness of HRD score to prospectively identify patients most likely to respond to the platinum-containing regimen. However, because of the small sample size and the exploratory nature of this study, care is necessary when interpreting the results. The ongoing translational study is expected to clarify the role of biomarkers.

We also found that, after the initial paclitaxel- or eribulinbased therapy, changes in tumor size at completion of neoadjuvant chemotherapy were similar between groups A1 and A2. The findings suggest the clinical usefulness of the new regimen in this population in terms of the $\mathrm{pCR}$ and tumor regression.

\section{Toxicity of eribulin- and paclitaxel-based regimens}

Regarding safety, peripheral sensory neuropathy is a common AE of microtubule-targeting agents. In the present study, the eribulin-based regimen more than halved the incidence of peripheral sensory neuropathy with the standard paclitaxel-based regimen ( $32 \%$ and $74 \%$, respectively). It affected less than a third of patients who received eribulin and was grade $\geq 3$ in none. This is consistent with the findings of previous studies, in which peripheral neuropathy was recorded for about a third of pretreated breast cancer patients who received eribulin monotherapy and was grade $\geq 3$ in $<10 \%$ [24, 44, 45]. We consider this lower-toxicity profile to be a benefit for TNBC patients for whom AEs are likely to have a greater negative impact. 
Table 5 Proportion of patients whose axillary lymph node status had become negative by the time of surgery ${ }^{\mathrm{a}}$

\begin{tabular}{lllllll}
\hline Group & $\begin{array}{l}\mathrm{N}(+) \text { at } \\
\text { screening }\end{array}$ & $\begin{array}{l}\text { Under- } \\
\text { went } \\
\text { surgery }\end{array}$ & ypN0 & $\begin{array}{l}\mathrm{N}(+) \text { at screen- } \\
\text { ing and underwent } \\
\text { surgery }\end{array}$ & $\begin{array}{l}\mathrm{N}(+) \text { at screening and under- } \\
\text { went surgery, and achieved } \\
\text { ypN0 }\end{array}$ & $\begin{array}{l}\text { Axillary lymph node status } \\
\text { had become negative, } \%(95 \% \\
\left.\mathrm{CI}^{\mathrm{b}}\right)\end{array}$ \\
\hline A1 $(n=23)$ & 8 & 23 & 19 & 8 & 7 & $88(47-100)$ \\
A2 $(n=22)$ & 8 & 22 & 16 & 8 & 6 & $75(35-97)$ \\
B1 $(n=27)$ & 11 & 24 & 17 & 9 & 5 & $45(17-77)$ \\
B2 $(n=27)$ & 10 & 25 & 15 & 9 & 2 & $20(3-56)$ \\
\hline
\end{tabular}

${ }^{\text {a } V a l u e s ~ a r e ~} n$ unless otherwise stated

${ }^{\mathrm{b}}$ Clopper-Pearson exact confidence interval

${ }^{\mathrm{c}}$ Fisher's exact test: group A1 versus A2 or group B1 versus group B2

Table 6 Incidence of adverse events ${ }^{\mathrm{a}, \mathrm{b}}$

\begin{tabular}{|c|c|c|c|c|c|c|c|c|}
\hline \multirow{2}{*}{ Adverse event } & \multicolumn{2}{|c|}{ Group A1 $(n=23)$} & \multicolumn{2}{|c|}{ Group A2 $(n=22)$} & \multicolumn{2}{|c|}{ Group B1 $(n=27)$} & \multicolumn{2}{|c|}{ Group B2 $(n=27)$} \\
\hline & Total & Grade $\geq 3$ & Total & Grade $\geq 3$ & Total & Grade $\geq 3$ & Total & Grade $\geq 3$ \\
\hline All adverse events & $23(100)$ & $19(83)$ & $22(100)$ & $20(91)$ & 27 (100) & $24(89)$ & 27 (100) & $25(93)$ \\
\hline Decreased neutrophil count & $19(83)$ & $13(57)$ & $19(86)$ & $16(73)$ & $25(93)$ & $23(85)$ & $25(93)$ & $22(81)$ \\
\hline Decreased white blood cell count & $17(74)$ & $5(22)$ & $15(68)$ & $10(45)$ & $24(89)$ & $15(56)$ & $21(78)$ & $11(41)$ \\
\hline Febrile neutropenia & $4(17)$ & $4(17)$ & $7(32)$ & $7(32)$ & $3(11)$ & $2(7)$ & $2(7)$ & $2(7)$ \\
\hline Anemia & $18(78)$ & $6(26)$ & $18(82)$ & $4(18)$ & $11(41)$ & 0 & $6(22)$ & 0 \\
\hline Thrombocytopenia & $8(35)$ & $1(4)$ & $11(50)$ & $2(9)$ & 0 & 0 & $6(22)$ & 0 \\
\hline Alopecia & $23(100)$ & 0 & $18(82)$ & 0 & 27 (100) & 0 & $23(85)$ & $1(4)$ \\
\hline Constipation & $19(83)$ & 0 & $20(91)$ & 0 & $16(59)$ & 0 & $16(59)$ & 0 \\
\hline Nausea & $17(74)$ & 0 & $16(73)$ & 0 & $18(67)$ & 0 & $16(59)$ & 0 \\
\hline Increased ALT & $10(43)$ & 0 & $16(73)$ & $3(14)$ & $14(52)$ & $6(22)$ & $16(59)$ & $4(15)$ \\
\hline Increased AST & $10(43)$ & 0 & $16(73)$ & 0 & $11(41)$ & 0 & 17 (63) & $3(11)$ \\
\hline Stomatitis & $11(48)$ & 0 & $16(73)$ & $1(5)$ & $12(44)$ & 0 & $9(33)$ & $2(7)$ \\
\hline Dysgeusia & $9(39)$ & 0 & $8(36)$ & 0 & $13(48)$ & 0 & $11(41)$ & 0 \\
\hline Malaise & $9(39)$ & 0 & $10(45)$ & 0 & $10(37)$ & 0 & $10(37)$ & 0 \\
\hline Peripheral sensory neuropathy & $17(74)$ & 0 & $7(32)$ & 0 & $6(22)$ & 0 & $7(26)$ & 0 \\
\hline Pyrexia & $12(52)$ & 0 & $8(36)$ & 0 & $8(30)$ & 0 & $4(15)$ & 0 \\
\hline Decreased appetite & $5(22)$ & 0 & $7(32)$ & 0 & $10(37)$ & 0 & $7(26)$ & 0 \\
\hline Diarrhea & $8(35)$ & 0 & $3(14)$ & 0 & $6(22)$ & 0 & $8(30)$ & 0 \\
\hline Vomiting & $8(35)$ & 0 & $10(45)$ & 0 & $4(15)$ & 0 & $2(7)$ & 0 \\
\hline Headache & $5(22)$ & 0 & $7(32)$ & 0 & $3(11)$ & 0 & $7(26)$ & 0 \\
\hline Increased GGT & $4(17)$ & 0 & $4(18)$ & 0 & $7(26)$ & $3(11)$ & $4(15)$ & $3(11)$ \\
\hline Insomnia & $5(22)$ & 0 & $7(32)$ & 0 & $3(11)$ & 0 & $3(11)$ & 0 \\
\hline Peripheral and facial oedema & $5(22)$ & 0 & $3(14)$ & 0 & $4(15)$ & 0 & $5(19)$ & 0 \\
\hline Fatigue & $5(22)$ & 0 & $3(14)$ & 0 & $2(7)$ & 0 & $2(7)$ & 0 \\
\hline Hand-foot syndrome & 0 & 0 & 0 & 0 & 0 & 0 & $11(41)$ & $1(4)$ \\
\hline Upper respiratory tract infection & $6(26)$ & 0 & $2(9)$ & 0 & $1(4)$ & 0 & $2(7)$ & 0 \\
\hline Acne-like dermatitis & $5(22)$ & 0 & $3(14)$ & 0 & $1(4)$ & 0 & $2(7)$ & 0 \\
\hline Arthralgia & $4(17)$ & 0 & $5(23)$ & 0 & $1(4)$ & 0 & 0 & 0 \\
\hline Rash & $3(13)$ & 0 & $5(23)$ & 0 & 0 & 0 & $1(4)$ & 0 \\
\hline Lymphocyte count decreased & $1(4)$ & $1(4)$ & $3(14)$ & $3(14)$ & $3(11)$ & 0 & 0 & 0 \\
\hline
\end{tabular}

ALT, alanine aminotransferase; AST, aspartate aminotransferase; GGT, $\gamma$-glutamyl transferase

${ }^{a}$ Adverse events of any grade occurring in $\geq 20 \%$ or grade $\geq 3$ events recorded for $\geq 10 \%$ of patients

${ }^{\mathrm{b}}$ Values are $n(\%)$ 
The low peripheral neuropathy incidence was also observed in group B, in which eribulin was given in combination with cyclophosphamide or capecitabine (22\% and $26 \%$ in groups B1 and B2, respectively). However, these regimens resulted in a low pCR rate (19\% in each group), which was below the threshold pCR rate (35\%). In a previous study, neoadjuvant eribulin plus cyclophosphamide resulted in a pCR rate of $13 \%$ in patients with invasive HER2-negative breast cancer [46]. Although our aim was to explore a less toxic regimen in this group, for which encouraging data were obtained, the finding of low pCR rate suggests these regimens to be unfeasible. Potential factors that may have affected sensitivity to chemotherapy in this group are low HRD score, tumors of lower histological grade (grade 3 in $67 \%$ and $44 \%$ in groups B1 and B2, respectively, versus $70 \%$ and $77 \%$ in groups $\mathrm{A} 1$ and $\mathrm{A} 2$, respectively), and older age (mean, $\sim 60$ years in group B versus $\sim 46$ years in group A). Because of the small sample size and phase II nature of the study, it is not possible to perform analyses to identify associations between these factors and the response. Further analyses, including long-term outcome data, may be needed.

The tolerability profiles of the eribulin-based regimens used in the present study were similar to those reported previously for eribulin-based regimens [24, 25] and FEC-docetaxel combinations [10-12], and there were no novel or unexpected AEs. All serious AEs were manageable, and there were no deaths related to treatment.

\section{Secondary endpoints}

As a secondary endpoint, BCSR was almost doubled with the eribulin-based regimen as compared with the standard paclitaxel-based regimen [point estimates: $26 \%$ (95\% CI, $10 \%-48 \%)$ and $55 \%(95 \% \mathrm{CI}, 32 \%-76 \%)$ in groups $\mathrm{A} 1$ and A2, respectively]. Tumor reduction is generally associated with increased BCSR. However, it should be noted that the decision between mastectomy and BCS is affected by many factors, including tumor site and resection area, breast size, risk of gBRCAm, widespread use of post-surgical breast reconstruction, and patient preference. These factors make it increasingly difficult to use BCSR as a measure of the success of neoadjuvant chemotherapy in clinical trials.

A more objective measure than BCSR for evaluating neoadjuvant therapy is the proportion of patients whose lymph node status changes from positive to negative. Changes in lymph node status reflect the efficacy of a chemotherapeutic regimen and can greatly influence prognosis [47]. In the present study, the likelihood of negative lymph node status being achieved by the time of surgery was similar between the regimens in each of groups A and B. The long-term prognosis of the patients is being followed to explore the effect of changes in lymph node status on prognosis.

\section{Limitations}

For the present study, fewer patients were enrolled than expected, and it took almost 2 years to recruit the requisite number. Nevertheless, we believe that our findings add to the literature suggesting potential benefits of clinically feasible and less toxic neoadjuvant chemotherapy for TNBC. A translational study is ongoing to investigate predictors of response.

\section{Conclusions}

In patients aged $<65$ years with high HRD score or gBRCAm, weekly paclitaxel plus carboplatin and eribulin plus carboplatin followed by anthracycline resulted in a pCR rate of $>60 \%$ and $>40 \%$, respectively, suggesting the potential usefulness of patient stratification using HRD score. In patients with HRD-negative tumors, pCR tended to be low. Neurotoxicity was less frequent with the eribulin-based regimen, which may be feasible as neoadjuvant chemotherapy for TNBC patients for whom AEs are likely to have a greater negative impact.

Supplementary Information The online version contains supplementary material available at https://doi.org/10.1007/s10549-021-06184-w.

Funding This study was a physician-led clinical trial funded by the Japan Breast Cancer Research Group and Eisai Co., Ltd.

\section{Declarations}

Conflict of interest Dr. Masuda: remuneration and research funding to institution from AstraZeneca, Chugai, Eli Lilly, and Pfizer; remuneration from Eisai and Takeda; research funding to institution from Daiichi Sankyo, Kyowa Kirin, MSD, Nippon Kayaku and Novartis. Dr. Bando: remuneration from AstraZeneca, Chugai, Eisai, Kyowa Kirin, Nippon Kayaku, Novartis, Pfizer, and Taiho. Dr. Yamanaka: remuneration from Chugai, Daiichi Sankyo, Eisai, Eli Lilly, Kyowa Kirin, Novartis, and Pfizer. Dr. Kadoya: none. Dr. Takahashi: remuneration from AstraZeneca, Eisai, Eli Lilly, and Pfizer. Dr. Nagai: remuneration from Chugai, Eisai, Eli Lilly, Novartis, Pfizer, and Taiho. Dr. Ohtani: remuneration from AstraZeneca, Chugai, Eisai, Eli Lilly, and Pfizer. Dr. Aruga: remuneration from Eisai, Eisai, and Pfizer. Dr. Suzuki: none. Dr. Kikawa: remuneration from Chugai, Eisai, Eli Lilly, Novartis, Pfizer, and Taiho. Dr. Yasojima: none. Dr. Kasai: funding from Eisai during the conduct of the study; remuneration from Chugai. Dr. Ishiguro: none. Dr. Kawabata: funding from Chugai, Daiichi Sankyo, MSD, and Novartis during the conduct of the study. Dr. Morita: remuneration from AstraZeneca, Bristol-Myers Squibb, Chugai, Eisai, Eli Lilly, MSD, Pfizer, and Taiho. Dr. Haga: none. Dr. Kataoka: none. Dr. Uozumi: consultant/advisory role at CAC Croit, Eisai, and Sawai. Dr. Ohno: funding from Eisai and Taiho; remuneration from AstraZeneca, Chugai, Eisai, Eli Lilly, and Pfizer. Dr. Toi: remuneration and funding from AstraZeneca, Chugai, Daiichi Sankyo, Eisai, Kyowa Kirin, Nippon Kayaku, Pfizer, Shimadzu, Taiho, Takeda, and Yakult; remuneration from Eli Lilly, Exact Sciences, Konica Minolta, MSD, and Novartis; funding from AFI technology, GL Sciences, JBCRG Association, Luxonus, and Shionogi; consultant/advisory role for 
Athenex Oncology, Bertis, Bristol-Myers Squibb, Daiichi Sankyo, Eli Lilly, Kansai Medical Net, Kyowa Kirin, Luxonus, and Terumo.

Ethical approval The study complied with the Declaration of Helsinki and the Ethical Guidelines for Clinical Research of the Ministry of Health, Labour and Welfare of Japan. The study protocol was reviewed and approved by the institutional review board of each participating institution. All patients provided written informed consent at primary registration. Some of the study results were presented as a Mini Oral session at the ESMO Virtual Congress 2020.

Open Access This article is licensed under a Creative Commons Attribution 4.0 International License, which permits use, sharing, adaptation, distribution and reproduction in any medium or format, as long as you give appropriate credit to the original author(s) and the source, provide a link to the Creative Commons licence, and indicate if changes were made. The images or other third party material in this article are included in the article's Creative Commons licence, unless indicated otherwise in a credit line to the material. If material is not included in the article's Creative Commons licence and your intended use is not permitted by statutory regulation or exceeds the permitted use, you will need to obtain permission directly from the copyright holder. To view a copy of this licence, visit http://creativecommons.org/licenses/by/4.0/.

\section{References}

1. Bianchini G, Baldo JM, Mayer IA, Sanders ME, Gianni L (2016) Triple-negative breast cancer: challenges and opportunities of a heterogeneous disease. Nat Rev Clin Oncol 13(11):674-690. https://doi.org/10.1038/nrclinonc.2016.66

2. Al-Mahmood S, Sapiezynski J, Garbuzenko OB, Minko T (2018) Metastatic and trip-negative breast cancer: challenges and treatment options. Drug Deliv Trans1 Res 8:1483-1507. https://doi. org/10.1007/s13346-018-0551-3

3. Early Breast Cancer Trialists' Collaborative Group (EBCTCG) (2005) Effects of chemotherapy and hormonal therapy for early breast cancer on recurrence and 15-year survival: an overview of the randomised trials. Lancet 365(9472):1687-1717. https://doi. org/10.1016/S0140-6736(05)66544-0

4. Liedtke C, Mazouni C, Hess KR, André F, Tordai A, Mejia JA, Symmans WF, Gonzalez-Angulo AM, Hennessy B, Green M, Cristofanilli M, Hortobagyi GN, Pusztai L (2008) Response to neoadjuvant therapy and long-term survival in patients with triplenegative breast cancer. J Clin Oncol 26(8):1275-1281. https://doi. org/10.1200/JCO.2007.14.4147

5. Early Breast Cancer Trialists' Collaborative Group (EBCTCG) (2012) Comparisons between different polychemotherapy regimens for early breast cancer: meta-analyses of long-term outcome among 100,000 women in 123 randomised trials. Lancet 379:432444. https://doi.org/10.1016/S0140-6736(11)61625-5

6. Cortazar P, Zhang L, Untch M, Mehta K, Costantino JP, Wolmark N, Bonnefoi H, Cameron D, Gianni L, Valagussa P, Swain SM, Prowell T, Loibl S, Wickerham DL, Bogaerts J, Baselga J, Perou C, Blumenthal G, Blohmer J, Mamounas EP, Bergh J, Semiglazov V, Justice R, Eidtmann H, Paik S, Piccart M, Sridhara R, Fasching PA, Slaerts L, Tang S, Gerber B, Geyer CE Jr, Pazdur R, Ditsch N, Rastogi P, Eiermann W, von Minckwitz G (2014) Pathological complete response and long-term clinical benefit in breast cancer: the CTNeoBC pooled analysis. Lancet 384(9938):164-172. https://doi.org/10.1016/S0140-6736(13)62422-8
7. Cleator S, Heller W, Coombes RC (2007) Triple-negative breast cancer: therapeutic options. Lancet Oncol 8(3):235-244. https:// doi.org/10.1016/S1470-2045(07)70074-8

8. Chen XS, Yuan Y, Garfield DH, Wu JY, Huang O, Shen KW (2014) Both carboplatin and bevacizumab improve pathological complete remission rate in neoadjuvant treatment of triple-negative breast cancer: a meta-analysis. PLoS ONE 9(9):e108405. https://doi.org/10.1371/journal.pone.0108405

9. Schmid P, Cortés J, Dent R, Pusztai L, McArthur HL, Kuemmel S, Bergh J, Denkert C, Park YH, Hui R, Harbeck N, Takahashi M, Foukakis T, Fasching PA, Cardoso F, Jia L, Karantza V, Zhao J, Aktan G, O'Shaughnessy J (2019) Keynote-522: Phase 3 study of pembrolizumab (pembro) + chemotherapy (chemo) vs placebo (pbo) + chemo as neoadjuvant treatment, followed by pembro vs pbo as adjuvant treatment for early triple-negative breast cancer (TNBC). https://oncologypro.esmo.org/meeting-resources/ esmo-2019-congress/KEYNOTE-522-Phase-3-study-of-pembr olizumab-pembro-chemotherapy-chemo-vs-placebo-pbo-chemoas-neoadjuvant-treatment-followed-by-pembro-vs-pbo-as-adjuv ant-treatment-for-early-triple-negative-breast-cancer-TNBC

10. Toi M, Nakamura S, Kuroi K, Iwata H, Ohno S, Masuda N, Kusama M, Yamazaki K, Hisamatsu K, Sato Y, Kashiwaba M, Kaise H, Kurosumi M, Tsuda H, Akiyama F, Ohashi T, Takatsuka T, Japan Breast Cancer Research Group (JBCRG) (2008) Phase II study of preoperative sequential FEC and docetaxel predicts of pathological response and disease free survival. Breast Cancer Res Treat. 110(3):531-539. https://doi.org/10.1007/ s10549-007-9744-z

11. Nakamura S, Masuda S, Iwata H, Toi M, Kuroi K, Kurozumi M, Tsuda H, Akiyama F (2008) Phase II trial of fluorouracil, epirubicin, cyclophosphamide (FEC) followed by docetaxel $100 \mathrm{mg} /$ $\mathrm{m}^{2}$ in primary operable breast cancer - JBCRG02. Jpn J Breast Cancer 23:111-117 ((In Japanese))

12. Iwata H, Sato N, Masuda N, Nakamura S, Yamamoto N, Kuroi K, Kurosumi M, Tsuda H, Akiyama F, Ohashi Y, Toi M (2011) Docetaxel followed by fluorouracil/epirubicin/cyclophosphamide as neoadjuvant chemotherapy for patients with primary breast cancer. Jpn J Clin Oncol 41(7):867-875. https://doi.org/10.1093/jjco/ hyr081

13. Kuroi K, Toi M, Ohno S, Nakamura S, Iwata H, Masuda N, Sato N, Tsuda H, Kurosumi M, Akiyama M (2015) Comparison of different definitions of pathologic complete response in operable breast cancer: a pooled analysis of three prospective neoadjuvant studies of JBCRG. Breast Cancer 22(6):586-595. https://doi.org/ 10.1007/s12282-014-0524-4

14. Masuda N, Higaki K, Takano T, Matsunami N, Morimoto T, Ohtani S, Mizutani M, Miyamoto T, Kuroi K, Ohno S, Morita S, Toi M (2014) A phase II study of metronomic paclitaxel/cyclophosphamide/capecitabine followed by 5 -fluorouracil/epirubicin/ cyclophosphamide as preoperative chemotherapy for triple-negative or low hormone receptor expressing/HER2-negative primary breast cancer. Cancer Chemother Pharmacol 74(2):229-238. https://doi.org/10.1007/s00280-014-2492-y

15. Jordan MA, Wilson L (2004) Microtubules as a target for anticancer drugs. Nat Rev Cancer 4(4):253-265. https://doi.org/10.1038/ $\operatorname{nrc} 1317$

16. Jordan MA, Kamath K, Manna T, Okouneva T, Miller HP, Davis C, Littlefield BA, Wilson L (2005) The primary antimitotic mechanism of action of the synthetic halichondrin E7389 is suppression of microtubule growth. Mol Cancer Ther 4(7):1086-1095. https:// doi.org/10.1158/1535-7163.MCT-04-0345

17. Okouneva T, Azarenko O, Wilson L, Littlefield BA, Jordan MA (2008) Inhibition of centromere dynamics by eribulin (E7389) during mitotic metaphase. Mol Cancer Ther 7:2003-2011. https:// doi.org/10.1158/1535-7163.MCT-08-0095 
18. Smith JA, Wilson L, Azarenko O, Zhu X, Lewis BM, Littlefield BA, Jordan MA (2010) Eribulin binds at microtubule ends to a single site on tubulin to suppress dynamic instability. Biochemistry 49(6):1331-1337. https://doi.org/10.1021/bi901810u

19. Dybdal-Hargreaves NF, Risinger AL, Mooberry SL (2015) Eribulin mesylate: mechanism of action of a unique microtubule targeting agent. Clin Cancer Res 21(11):2445-2452. https://doi.org/10. 1158/1078-0432.CCR-14-3252

20. Ueda S, Saeki T, Takeuchi H, Shigekawa T, Yamane T, Kuji I, Osaki A (2016) In vivo imaging of eribulin-induced reoxygenation in advanced breast cancer patients: a comparison to bevacizumab. Br J Cancer 114(11):1212-1218. https://doi.org/10.1038/ bjc. 2016.122

21. Yoshida T, Kuznetsov G, Kimura T, Sugi NH, Shimizu H, Ozawa Y, Sato Y, Uehara T, Watanabe H, Takahashi K, Matsuura K, Uesugi M, Toyama O, Yanagimachi M, Funahashi Y, Matsui J (2013) Abstract A296: Eribulin mesylate suppresses experimental metastasis in the MX-1 human breast cancer model by reversing phenotypic states between epithelial-mesenchymal transition (EMT) to mesenchymal-epithelial transition (MET). Mol Cancer Ther 12:A296. https://doi.org/10.1158/1535-7163. TARG-13-A296

22. Yoshida T, Ozawa Y, Kimura T, Sato Y, Kuznetsov G, Xu S, Uesugi M, Agoulnik S, Taylor N, Funahashi Y, Matsui J (2014) Eribulin mesilate suppresses experimental metastasis of breast cancer cells by reversing phenotype from epithelial-mesenchymal transition (EMT) to mesenchymal-epithelial transition (MET) states. Br J Cancer 110(6):1497-1405. https://doi.org/10.1038/bjc. 2014.80

23. Yardley DA, Peacock N, Daniel B, Anz B, Molthrop DC, Shroff SK, Young R, Jankov A, Vander Woude A, Shastry M, Pasek J, DeBusk LM, Hainsworth JD (2020) Phase II trial of eribulin in patients who do not achieve pathologic complete response (pCR) following neoadjuvant chemotherapy. Breast Cancer Res Treat 180(3):647-655. https://doi.org/10.1007/s10549-020-05563-z

24. Cortes J, O'Shaughnessy J, Loesch D, Blum JL, Vahdat LT, Petrakova K, Chollet P, Manikas A, Diéras V, Delozier T, Vladimirov V, Cardoso F, Koh H, Bougnoux P, Dutcus CE, Seegobin S, Mir D, Meneses N, Wanders J, Twelves C, EMBRACE (Eisai Metastatic Breast Cancer Study Assessing Physician's Choice Versus E7389) investigators (2011) Eribulin monotherapy versus treatment of physician's choice in patients with metastatic breast cancer (EMBRACE): a phase 3 open-label randomised study. Lancet 377(9769):914-923. https://doi.org/10.1016/S0140-6736(11) 60070-6

25. Twelves C, Cortes J, Vahdat L, Olivo M, He Y, Kaufman PA, Awada A (2014) Efficacy of eribulin in women with metastatic breast cancer: a pooled analysis of two phase 3 studies. Breast Cancer Res Treat 148:553-561. https://doi.org/10.1007/ s10549-014-3144-y

26. Zhao Y, Shen Y, Pleasance E, Kasaian K, Leelakumari S, Jones M, Bose P, Ch'ng C, Reisle C, Eirew P, Corbett R, Mungall KL, Thiessen N, Ma Y, Schein JE, Mungall AJ, Zhao Y, Moore RA, Den Brok W, Wilson S, Villa D, Shenkier T, Lohrisch C, Chia S, Yip S, Gelmon K, Lim H, Renouf D, Sun S, Schrader KA, Young S, Bosdet I, Karsan A, Laskin J, Marra MA, Jones SJM (2017) Homologous recombination deficiency and platinumbased therapy outcomes in advanced breast cancer. Clin Cancer Res 23(24):7521-7530. https://doi.org/10.1158/1078-0432. CCR-17-1941

27. Tutt A, Tovey H, Cheang MCU, Kernaghan S, Kilburn L, Gazinska P, Owen J, Abraham J, Barrett S, Barrett-Lee P, Brown R, Chan S, Dowsett M, Flanagan JM, Fox L, Grigoriadis A, Gutin A, Harper-Wynne C, Hatton MQ, Hoadley KA, Parikh J, Parker P,
Perou CM, Roylance R, Shah V, Shaw A, Smith IE, Timms KM, Wardley AM, Wilson G, Gillett C, Lanchbury JS, Ashworth A, Rahman N, Harries M, Ellis P, Pinder SE, Bliss JM (2018) Carboplatin in BRCA1/2-mutated and triple-negative breast cancer BRCAness subgroups: the TNT Trial. Nat Med 24(5):628-637. https://doi.org/10.1038/s41591-018-0009-7

28. Timms KM, Abkevich V, Hughes E, Neff C, Reid J, Morris B, Kalva S, Potter J, Tran TV, Chen J, Iliev D, Sangale Z, Tikishvili E, Perry M, Zharkikh A, Gutin A, Lanchbury JS (2014) Association of BRCA1/2 defects with genomic scores predictive of DNA damage repair deficiency among breast cancer subtypes. Breast Cancer Res 16:475

29. Ando M, Yamauchi H, Aogi K, Shimizu S, Iwata H, Masuda N, Yamamoto N, Inoue K, Ohono S, Kuroi K, Hamano T, Sukigara T, Fujiwara Y (2014) Randomized phase II study of weekly paclitaxel with and without carboplatin followed by cyclophosphamide/epirubicin/5-fluorouracil as neoadjuvant chemotherapy for stage II/IIIA breast cancer without HER2 overexpression. Breast Cancer Res Treat 145(2):401-409. https://doi.org/10. 1007/s10549-014-2947-1

30. Von Minckwitz G, Timms K, Untch M, Elkin EP, Fasching PA, Schneeweiss A, Salat C, Rezai M, Blohmer JU, Zahm DM, Jackisch C, Gerber B, Klare P, Kümmel S, Eidtmann H, Paepke S, Reid JE, Nekljudova V, Hartman A-R, Loibl S (2015) Prediction of pathological complete response (pCR) by homologous recombination deficiency (HRD) after carboplatin-containing neoadjuvant chemotherapy in patients with TNBC: results from GeparSixto. J Clin Oncol 33(15):1004-1004. https://doi.org/10. 1200/jco.2015.33.15_suppl.1004

31. Loibl S, Weber KE, Timms KM, Elkins EP, Hahnen E, Faschings PA, Lederer B, Denkert C, Schneeweiss A, Braun S, Salat CT, Rezai M, Blohmer JU, Zahm DM, Jackisch C, Gerber B, Klare P, Kümmel S, Schem C, Paepke S, Schmutzler R, Rheim K, Penn S, Reid J, Nekljudova V, Hartman A-R, von Minckwitz G, Untch M, Investigators of the German Breast Group, Arbeitsgemeinschaft Gynäkologische Onkologie-Breast Study Group (2018) Survival analysis of carboplatin added to an anthracycline/taxane-based neoadjuvant chemotherapy and HRD score as predictor of response - final results from GeparSixto. Ann Oncol 29(12):2341-2347

32. Kaklamani VG, Jeruss JS, Hughes E, Siziopikou K, Timms KM, Gutin A, Abkevich V, Sangale Z, Solimeno C, Brown KL, Jones J, Hartman AR, Meservey C, Jovanovic B, Helenowski I, Khan SA, Bethke K, Hansen N, Uthe R, Giordano S, Rosen S, Hoskins K, Von Roenn J, Jain S, Parini V, Gradishar W (2015) Phase II neoadjuvant clinical trial of carboplatin and eribulin in women with triple negative early-stage breast cancer (NCT01372579). Breast Cancer Res Treat 151(3):629-638. https://doi.org/10.1007/s10549-015-3435-y

33. Gavila J, Seguí MÁ, Calvo L, López T, Alonso JJ, Farto M, Sánchez-de la Rosa R (2017) Evaluation and management of chemotherapy-induced cardiotoxicity in breast cancer: a Delphi study. Clin Transl Oncol 19(1):91-104. https://doi.org/10.1007/ s12094-016-1508-y

34. Cai F, Luis MAF, Lin X, Wang M, Cai L, Cen C, Biskup E (2019) Anthracycline-induced cardiotoxicity in the chemotherapy treatment of breast cancer: preventive strategies and treatment. Mol Clin Oncol 11(1):15-23. https://doi.org/10.3892/ mco.2019.1854

35. Shimada K, Ishikawa T, Kita K, Narui K, Sugae S, Shimizu D, Tanabe M, Sasaki T, Chishima T, Ichikawa Y, Endo I (2015) Neoadjuvant docetaxel/cyclophosphamide in triple-negative breast cancer: predictive value of class III- $\beta$ tubulin and non-basal subtype. Anticancer Res 35(2):907-912 
36. Ishikawa T, Narui K, Tanabe M, Kida K, Oba MS, Yamada A, Ichikawa Y, Endo I (2016) BRCAness is beneficial for indicating triple negative breast cancer patients resistant to taxane. Eur J Surg Oncol 42(7):999-1001. https://doi.org/10.1016/j.ejso.2016. 02.246

37. Nakatsukasa K, Koyama H, Oouchi Y, Imanishi S, Mizuta N, Sakaguchi K, Fujita Y, Fujiwara I, Kotani T, Matsuda T, Fukuda K, Morita M, Kawakami S, Kadotani Y, Konishi E, Yanagisawa A, Taguchi T (2017) Docetaxel and cyclophosphamide as neoadjuvant chemotherapy in HER2-negative primary breast cancer. Breast Cancer 24(1):63-68. https://doi.org/10.1007/ s12282-016-0666-7

38. Hattori M, Ishiguro H, Masuda N, Yoshimura A, Ohtani S, Yasojima H, Morita S, Ohno S, Iwata H (2018) Phase I dose-finding study of eribulin and capecitabine for metastatic breast cancer: JBCRG-18 cape study. Breast Cancer 25(1):108-117. https://doi. org/10.1007/s12282-017-0798-4

39. Jiang T, Shi W, Wali VB, Pongor LS, Li C, Lau R, Gyõrffy B, Lifton RP, Symmans WF, Pusztai L, Hatzis C (2016) Predictors of chemosensitivity in triple negative breast cancer: an integrated genomic analysis. PLOS. https://doi.org/10.1371/journal.pmed. 1002193

40. Telli ML, Hellyer J, Audeh W, Jensen KC, Bose S, Timms KM, Gutin A, Abkevich V, Peterson RN, Neff C, Hughes E, Sangale Z, Jones J, Hartman AR, Chang PJ, Vinayak S, Wenstrup R, Ford JM (2018) Homologous recombination deficiency (HRD) status predicts response to standard neoadjuvant chemotherapy in patients with triple-negative or BRCA1/2 mutation-associated breast cancer. Breast Cancer Res Treat 168(3):625-630. https://doi.org/10. 1007/s10549-017-4624-7

41. National Cancer Institute Common Terminology Criteria for Adverse Events, version 4.0 (Japanese Clinical Oncology Group edition). http://www.jcog.jp/doctor/tool/CTCAEv4J_20170310_ miekeshi.pdf (In Japanese).

42. Naito Y, Yonemori K, Yamamoto H, Takahashi M, Nakamura R, Masuda N, Aogi K, Yamanaka T, Ito Y, Yoshida A, Tsuda H,
Kuchiba A, Hata T, Tamura K, Fujiwara T (2018) Neoadjuvant eribulin in early triple-negative breast cancer. Proceedings of the European Breast Cancer Conference. https://doi.org/10.1016/ S0959-8049(18)30520-3

43. Poggio F, Bruzzone M, Ceppi M, Pondé NF, La Valle G, Del Mastro L, de Azambuja E, Lambertini M (2018) Platinum-based neoadjuvant chemotherapy in triple-negative breast cancer: a systematic review and meta-analysis. Ann Oncol 29(7):1497-1508. https://doi.org/10.1093/annonc/mdy 127

44. Vahdat LT, Garcia AA, Vogel C, Pellegrino C, Lindquist DL, Iannotti N, Gopalakrishna P, Sparano JA (2013) Eribulin mesylate versus ixabepilone in patients with metastatic breast cancer: a randomized phase II study comparing the incidence of peripheral neuropathy. Breast Cancer Res Treat 140(2):341-351. https://doi. org/10.1007/s10549-013-2574-2

45. Gamucci T, Michelotti A, Pizzuti L, Mentuccia L, Landucci E, Sperduti I, Di Lauro L, Fabi A, Tonini G, Sini V, Salesi N, Ferrarini I, Vaccaro A, Pavese I, Veltri E, Moscetti L, Marchetti P, Vici P (2014) Eribulin mesylate in pretreated breast cancer patients: a multicenter retrospective observational study. J Cancer 5(5):320-327. https://doi.org/10.7150/jca.8748

46. Yardley DA, Shipley D, Zubkus J, Wright GL, Ward PJ, Mani A, Shastry M, Finney L, DeBusk L, Hainsworth JD (2019) A randomized phase II study of eribulin/cyclophosphamide or docetaxel/ cyclophosphamide as neoadjuvant therapy in operable HER2-negative breast cancer. Clin Breast Cancer 19(1):1-9. https://doi.org/ 10.1016/j.clbc.2018.08.006

47. Ai X, Liao X, Wang M, Hu Y, Li J, Zhang Y, Tang P, Jiang J (2020) Prognostic value of lymph node ratio in breast cancer patients with adequate pathologic evidence after neoadjuvant chemotherapy. Med Sci Monit. https://doi.org/10.12659/MSM. 922420

Publisher's Note Springer Nature remains neutral with regard to jurisdictional claims in published maps and institutional affiliations. 


\section{Authors and Affiliations}

\section{Norikazu Masuda ${ }^{1}$ ( $\cdot$ Hiroko Bando ${ }^{2} \cdot$ Takashi Yamanaka $^{3} \cdot$ Takayuki Kadoya $^{4} \cdot$ Masato Takahashi $^{5}$. Shigenori E. Nagai ${ }^{6}$. Shoichiro Ohtani ${ }^{7}$. Tomoyuki Aruga $^{8}$ - Eiji Suzuki $^{9}$. Yuichiro Kikawa ${ }^{10}$ - Hiroyuki Yasojima ${ }^{1}$. Hiroi Kasai $^{11} \cdot$ Hiroshi Ishiguro $^{12}$ • Hidetaka Kawabata ${ }^{13}$ - Satoshi Morita ${ }^{14}$. Hironori Haga ${ }^{15}$. Tatsuki R. Kataoka ${ }^{15}$. Ryuji Uozumi ${ }^{14}$. Shinji Ohno ${ }^{16} \cdot$ Masakazu Toi $^{9}$}

1 Department of Surgery, Breast Oncology, NHO Osaka National Hospital, 2-1-14 Hoenzaka, Chuou-ku, Osaka, Japan

2 Breast and Endocrine Surgery, Faculty of Medicine, University of Tsukuba, Ibaraki, Japan

3 Breast and Endocrine Surgery, Kanagawa Cancer Center, Kanagawa, Japan

4 Department of Breast Surgery, Hiroshima University Hospital, Hiroshima University, Hiroshima, Japan

5 Department of Breast Surgery, NHO Hokkaido Cancer Center, Hokkaido, Japan

6 Division of Breast Oncology, Saitama Cancer Center, Saitama, Japan

7 Department of Breast Surgery, Hiroshima City Hiroshima Citizens Hospital, Hiroshima, Japan

8 Breast Surgery Division, Tokyo Metropolitan Cancer and Infectious Diseases Center Komagome Hospital, Tokyo, Japan
9 Breast Cancer Unit, Kyoto University Hospital, Graduate School of Medicine, Kyoto University, Kyoto, Japan

10 Department of Breast Surgery, Kobe City Medical Center General Hospital, Hyogo, Japan

11 Institute for Advancement of Clinical and Translational Science, Kyoto University Hospital, Kyoto, Japan

12 Breast Oncology Service, Saitama Medical University International Medical Center, Saitama, Japan

13 Department of Breast and Endocrine Surgery, Toranomon Hospital, Tokyo, Japan

14 Department of Biomedical Statistics and Bioinformatics, Kyoto University Graduate School of Medicine, Kyoto, Japan

15 Department of Diagnostic Pathology, Kyoto University Hospital, Kyoto, Japan

16 Breast Oncology Center, The Cancer Institute Hospital of JFCR, Tokyo, Japan 